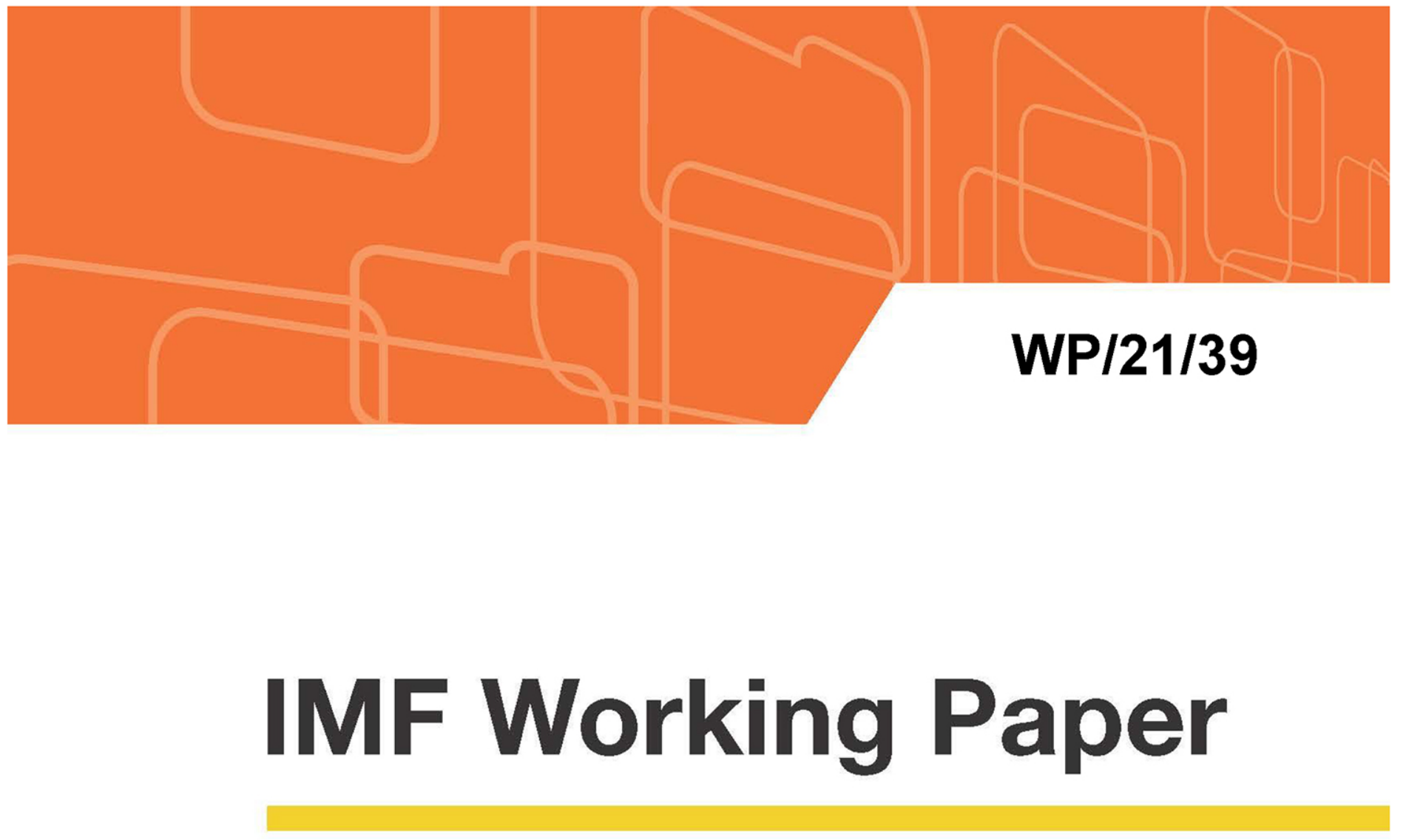

\title{
The Impact of $r-g$ on the Euro-Area Government Spending Multiplier
}

by Mario Di Serio, Matteo Fragetta and Giovanni Melina

IMF Working Papers describe research in progress by the author(s) and are published to elicit comments and to encourage debate. The views expressed in IMF Working Papers are those of the author(s) and do not necessarily represent the views of the IMF, its Executive Board, or IMF management. 


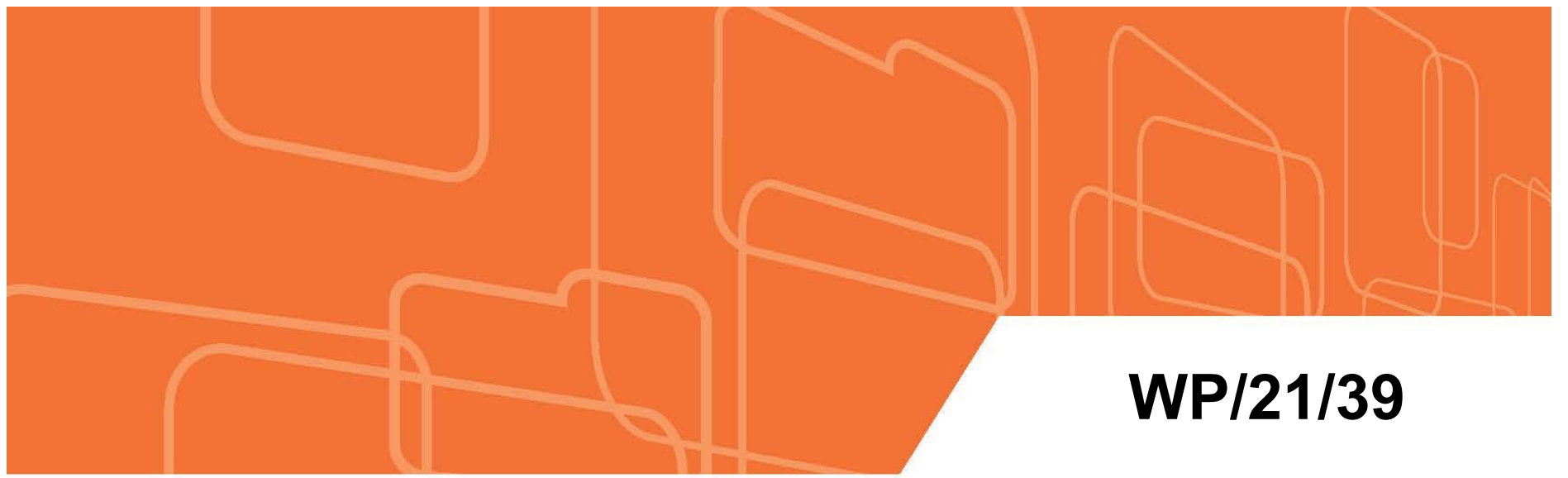

\section{IMF Working Paper}

\section{The Impact of $r-g$ on the Euro-Area Government Spending Multiplier}

by Mario Di Serio, Matteo Fragetta and Giovanni Melina

IMF Working Papers describe research in progress by the author(s) and are published to elicit comments and to encourage debate. The views expressed in IMF Working Papers are those of the author(s) and do not necessarily represent the views of the IMF, its Executive Board, or IMF management. 


\title{
IMF Working Paper
}

\author{
Research Department
}

\section{The Impact of $r$-g on the Euro-Area Government Spending Multiplier* Prepared by Mario Di Serio, Matteo Fragetta and Giovanni Melina}

\author{
Authorized for distribution by Chris Papageorgiou
}

February 2021

\section{IMF Working Papers describe research in progress by the author(s) and are published to elicit comments and to encourage debate. The views expressed in IMF Working Papers are those of the author(s) and do not necessarily represent the views of the IMF, its Executive Board, or IMF management.}

\begin{abstract}
We compute government spending multipliers for the Euro Area (EA) contingent on the interestgrowth differential, the so-called $r-g$. Whether the fiscal shock occurs when $r-g$ is positive or negative matters for the size of the multiplier. Median estimates vary conditional on the specification, but the difference between multipliers in the negative and positive $r$ - $g$ regimes differs systematically from zero with very high probability. Over the medium run ( 5 years), median cumulated multipliers range between 1.22 and 1.77 when $r-g$ is negative, and between 0.51 and 1.26 when $r-g$ is positive. We show that the results are not driven by the state of the business cycle, the monetary policy stance, or the level of government debt, and that the multiplier is inversely correlated with $r$ - $g$. The calculations are based on the estimates of a factor-augmented interacted panel vector-autoregressive model. The econometric approach deals with several technical problems highlighted in the empirical macroeconomic literature, including the issues of fiscal foresight and limited information.
\end{abstract}

JEL Classification Numbers: C32, C33, C38, E62, H63.

Keywords: Fiscal multiplier, Panel VAR, Factor models, Euro Area, $r-g$.

Author's E-Mail Addresses: mdiserio@unisa.it; mfragetta@unisa.it; gmelina@imf.org.

\footnotetext{
* Di Serio: Università degli Studi di Salerno, Italy; Fragetta: Università degli Studi di Salerno, Italy and Instituto Universitário de Lisboa, Portugal; Melina: Research Department, International Monetary Fund and CESifo, Center for Economic Studies and Ifo Institute, Germany. Comments and suggestions by Alexandra Fotiou, Raju Huidrom, Andy Jobst, Asghar Shahmoradi, Moez Souissi, and Rachel van Elkan are gratefully acknowledged. The usual disclaimer applies.
} 


\section{Contents}

1 Introduction $\quad \underline{5}$

2 Methodology $\underline{8}$

2.1 Empirical Model . . . . . . . . . . . . . . . . 8

2.2 Baseline Specification, Data and Computation of Cumulated Government Spending Multipliers . . . . . . . . . . . . . . . . . . . $\underline{9}$

3 Results $\quad \underline{11}$

3.1 Impulse Responses . . . . . . . . . . . . . . . . . . . . . . $\underline{12}$

3.2 Cumulated Government Spending Multipliers . . . . . . . . . . . . 12

3.3 Impact of the State of the Business Cycle, the Monetary Policy Stance, and the Level of Public Debt . . . . . . . . . . . . . . . . $\underline{15}$

4 Robustness Checks $\quad \underline{19}$

5 Conclusions $\quad \underline{23}$

$\begin{array}{lr}\text { References } & \underline{24}\end{array}$

$\begin{array}{ll}\text { Appendix } & \underline{27}\end{array}$

$\begin{array}{lr}\text { A Data } & \underline{27}\end{array}$

A.1 Endogenous Variables . . . . . . . . . . . . . . . . . . $\underline{27}$

A.2 Exogenous Variables . . . . . . . . . . . . . . . . . . $\underline{27}$

A.3 Informational Dataset . . . . . . . . . . . . . . . $\underline{28}$

B Inference and Identification $\quad \underline{28}$

\section{List of Tables}

1 Cumulated Government Spending Multipliers . . . . . . . . . . . 14

2 Cumulated Government Spending Multipliers: Alternative Variables in the Interaction Term . . . . . . . . . . . . . . . . . . . 18

3 Robustness Checks on the Cumulated Government Spending Multipliers . . $\underline{22}$ 


\section{List of Figures}

1 Government Debt, $r-g$, and Cyclically-Adjusted Primary Balances (CAPB) in the Euro Area . . . . . . . . . . . . . . . . . . . $\underline{6}$

2 Impulse Responses to a Government Spending Shock . . . . . . . . . . . 13

3 Distributions of Differences in Cumulated Government Spending Multipliers between Negative and Positive $r-g$ regimes . . . . . . . . . . . . . $\underline{15}$

4 Historical Evolution of Cumulated Government Spending Multipliers . . . . 16

5 Impulse Responses of Private Investment and Consumption to a Government Spending Shock . . . . . . . . . . . . . . . . . . $\underline{21}$ 


\section{Introduction}

In academic and policy circles, the interest rate-growth differential $(r-g)$ has been under close scrutiny in the past few years. With interest rates persistently low, $r-g$ has turned negative in many countries after the Global Financial Crisis (GFC), providing arguments for fiscal stimuli to boost economic activity (Blanchard, 2019). At the same time, government debt has risen to historically high levels, casting doubts on debt sustainability, given that a negative $r-g$ may turn positive in response to adverse shocks (Rogoff, 2020). This debate could not be more central in the context of the economic fallout of the COVID-19 pandemic, because countries have increased, and will likely continue to increase, government expenditures to face the health emergency, mitigate the economic collapse, and accelerate the recovery.

Whether fiscal expansions will deliver the intended objectives boils down to the extent to which they are able to boost GDP, the relationship captured by the concept of fiscal multiplier. High fiscal multipliers would benefit also debt sustainability through the negative effect that GDP growth has on $r-g$. The literature has investigated the size of fiscal multipliers from many different angles, focusing recently on the state dependency of multipliers on a variety of macroeconomic indicators (the business cycle, effective lower bound (ELB) regimes, the level of public debt, among others). However, to our knowledge, there is no contribution linking the size of the fiscal multiplier to $r-g$. This paper deals with this matter from an empirical viewpoint by posing the following research question: does the level of $r-g$ affect the size of the government spending multiplier?

According to textbook macroeconomics, at every point in time, the debt stock will grow by the existing debt stock multiplied by $r-g$, net of the primary budget balance (with debt and the primary balance expressed as fractions of GDP). Therefore, government debt will tend to grow when $r-g$ is positive, and it will tend to fall when $r-g$ is negative. In addition, the higher $r-g$, the higher the primary budget balance a government will need to run in the future to stabilize its debt. Forward-looking private agents will incorporate this mechanism in their expectations and increase their savings. We conjecture that this behavior should curb the size of the fiscal multiplier.

We use data from ten EA countries (Austria, Belgium, Finland, France, Germany, Ireland, Italy, Netherlands, Portugal and Spain) that were part of the European Monetary Union (EMU) since its inception. ${ }^{1}$ This choice yields a balanced panel dataset with quarterly observations on countries that experienced a wide variety of discretionary fiscal shocks over

\footnotetext{
${ }^{1}$ In line with Auerbach and Gorodnichenko (2013), we exclude Luxembourg being it a small economy with large and volatile changes in government spending series.
} 
Figure 1: Government Debt, $r-g$, and Cyclically-Adjusted Primary Balances (CAPB) in the Euro Area

(a) Government debt-to-GDP ratio and $r-g$

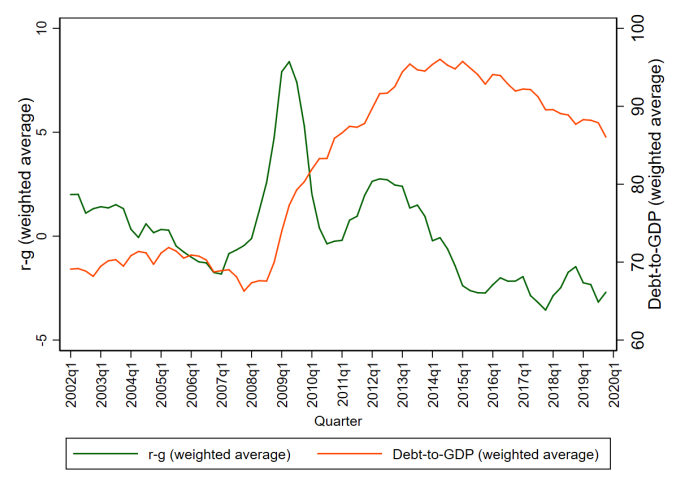

(b) Correlations between $r-g$ and CAPB

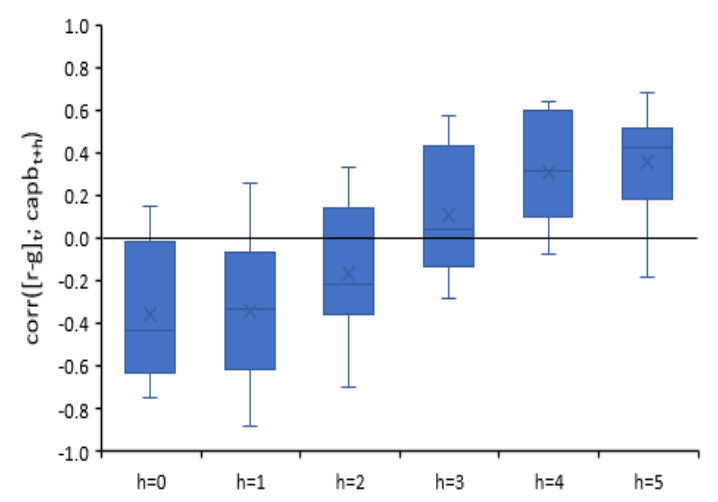

Sources: Datastream, IMF and authors' calculations.

Notes: In panel (a), $r-g$ is computed as explained in Section 2.2, and both lines represent weighted averages of 10 EA countries (Austria, Belgium, Finland, France, Germany, Ireland, Italy, Netherlands, Portugal and Spain), using national GDPs as weights. Panel (b) reports dynamic correlations between $r-g$ at time $t$ and the IMF's cyclically adjusted primary balance (fraction to potential GDP) at time $t+h$, with $h=0,1, \ldots, 5$. In each box, the horizontal line $(\mathrm{x})$ represents the median (average) correlation across the same $10 \mathrm{EA}$ countries; the upper and lower edges of each box represent the top and bottom quartiles of the correlations, respectively; and the top and bottom markers denote the maximum and minimum correlation, respectively.

a period of time in which they were exposed to the same monetary policy stance. In line with other advanced economies, the EA exhibits an increase in the debt ratio and a fall in $r-g$ after the GFC (Figure 1, Panel a). Moreover, the theoretical prediction of higher $r-g$ being associated with higher future primary balances is consistent with EA data. Figure 1 (Panel b) reports the distributions of dynamic correlations between $r-g$ and the cyclicallyadjusted primary balance (CAPB), a common indicator of the discretionary fiscal policy stance. While the two variables tend to display a negative contemporaneous correlation, ${ }^{2}$ the correlation tends to turn positive over the medium term (five years). In other words, a higher $r-g$ at time $t$ tend to be associated with a stronger discretionary fiscal adjustment down the road. ${ }^{3}$

Our empirical findings are consistent with the abovementioned theoretical considerations and can be summarized as follows: (i) the size of the average cumulated multiplier depends on the $r-g$ regime, with the difference between the size of the multiplier in the negative and positive $r-g$ regimes being economically important and different from zero with high

\footnotetext{
${ }^{2}$ The negative contemporaneous correlation captures the countercyclical nature of fiscal policy in advanced economies. When the economy is growing (large $g$ ), the fiscal stance tends to be tight (large CAPB) and $r-g$ tends to be low.

${ }^{3}$ Note that a higher CAPB represents higher taxes and/or lower non-interest expenditures, once the business cycle has been taken into account.
} 
probability; (ii) this difference increases at time horizons beyond the first year; (iii) median estimates of the multipliers vary conditional on the specification: over the medium run ( 5 years), median cumulated multipliers range between 1.22 and 1.77 when $r-g$ is negative, and between 0.51 and 1.26 when $r-g$ is positive; (iv) more generally, the multiplier is inversely correlated with the level of $r-g$. These results survive a number of robustness checks, while placebo-like tests confirm that the findings are not driven by the state of the business cycle, the monetary policy stance, or the level of government debt.

The estimates are derived from a factor-augmented interacted panel vector-autoregressive model purified of expectations (FAIPVAR-X). This setup is an extension of the I-VAR model by Caggiano et al. (2017), which we recently used to estimate fiscal multipliers at the ELB for the EA (Amendola et al., 2020). Using this framework has four advantages. First, the panel dimension allows exploiting quarterly data of the abovementioned ten EA countries. Second, the presence of an interaction term allows capturing nonlinearities and estimating the reaction of the variables of interest to a government spending shock conditional on $r-g$, which we endogenize in our econometric model. Third, augmenting the specification with factors extracted from a large number of macroeconomic variables mitigates limited information concerns. In fact, there is likely important information that we do not explicitly include in our model, but that might have been used by economic agents in making their choices (see Bernanke et al., 2005; Stock and Watson, 2005; Fragetta and Gasteiger, 2014). Fourth, including forecasts of government spending formed over the past year as an exogenous variable purges government spending shocks from a considerable fraction of its anticipated component and mitigates the issue of fiscal foresight (see, e.g., Forni and Gambetti (2010), among others).

Our paper is related to two strands of the literature. The first strand comprises the contributions analyzing the relationship between $r-g$ and debt sustainability. Blanchard (2019) shows that, in countries such as the U.S., with safe interest rates expected to remain below growth rates for a long time, debt rollovers without a later increase in taxes may be feasible. The evidence on advanced economies hints that a negative $r-g$ may persist in the long run (Barrett, 2018). However, there is no guarantee, given that $r-g$ may quickly turn positive due to large adverse shocks (Rogoff, 2020), especially if government debt is high (Lian et al., 2020). Moreover, the historical experience of advanced and emerging economies suggests that a negative $r-g$ is not a sufficient condition for debt sustainability (Mauro and Zhou, 2020). The second strand of the literature encompasses studies on the state dependency of fiscal multipliers on a variety of macroeconomic indicators. Common conditioning variables are the state of the business cycle (Auerbach and Gorodnichenko, 2012; Batini et al., 2012; Caggiano et al., 2015; Ramey and Zubairy, 2018, among others); 
monetary policy regimes, with a focus on the ELB (Miyamoto et al., 2018; Amendola et al., 2020; Bonam et al., 2020, among others); and the level of government debt ( Kirchner et al., 2010; Nickel and Tudyka, 2014, among others). Our paper bridges these two strands of the literature for the first time, by linking the size of the government spending multiplier to $r-g$.

The remainder of the paper is structured as follows. Section 2 explains the empirical methodology and the econometric specification. Section 3 reports the results. Section 4 presents robustness checks. Finally, Section 5 concludes. Data sources are appended to the paper.

\section{Methodology}

\subsection{Empirical Model}

The empirical model is an extension of the factor-augmented interacted panel vector-autoregressive model purified of expectations (FAIPVAR-X) of Amendola et al. (2020), which in turn builds on the Interacted Vector Auto-Regressive (I-VAR) framework developed by Caggiano et al. (2017). To allow for as much heterogeneity as possible, we utilize a panel model with fixed effects and heterogeneous slopes, which we estimate using the mean group estimator. This estimator has been shown to perform better than alternative estimators in dynamic panels (see, e.g., Pesaran and Smith, 1995 and Canova and Ciccarelli, 2013, among others).

The model specification takes the following reduced form:

$$
\begin{aligned}
Y_{i, t} & =\sum_{i=1}^{N} C_{i} D_{i, j}+\sum_{i=1}^{N} \sum_{k=1}^{L} A_{i, k} D_{i, j} Y_{i, t-k}+\left[\sum_{i=1}^{N} \sum_{k=1}^{L} A_{i, k}^{1} D_{i, j} G_{i, t-k} \times(r-g)_{i, t-k}\right] \\
& +\sum_{i=1}^{N} V_{i} D_{i, j} f_{(t \mid t-1: t-4)}+V^{1} z_{t-1}+u_{i, t}
\end{aligned}
$$

where $t=1, \ldots, T$ denotes the time dimension; $i=1, \ldots, N$ denotes the country dimension; and $k=1, \ldots, L$ represents the lag structure. The vector of endogenous variables is denoted by $Y_{i, t}$; the interaction term is represented by $G_{i, t-k} \times(r-g)_{i, t-k}$; while the vectors of two sets of exogenous variables are denoted by $f_{(t-1: t-4)}$ (discussed in Subsection 2.2) and $z_{t-1}$ (foreign exogenous variables, also discussed in Subsection 2.2). Furthermore, coefficient $C_{i}$ is the country-specific intercept of country $i ; A_{i, k}$ is the matrix of autoregressive coefficients attached to the endogenous variables; $A_{i, k}^{1}$ is the matrix of country-specific coefficients of 
the interaction term; $V_{i}$ is the matrix of country-specific coefficients attached to the first set of exogenous variables; $V^{1}$ represents the pooled estimated coefficients of the another set of exogenous variables; ${ }^{4} D_{i, j}$ is an indicator variable for each country (equal to 1 if $i=j$, and 0 otherwise); and, lastly, $u_{i, t}$ is a vector of normally distributed residuals with mean zero and covariance matrix $\Sigma_{i}$.

Given that the model requires the estimation of a large number of parameters, for the sake of parsimony, we produce the results with a uniform lag structure of one quarter $(L=1) .^{5}$ This model is well suited to our purposes for the presence of an interaction term which involves two endogenous variables. The first variable is a proxy for government spending, $G$, the exogenous variation of which we aim at identifying. The second variable is a proxy of the interest-growth differential used as a conditioning variable, $(r-g){ }^{6}$

\subsection{Baseline Specification, Data and Computation of Cumulated Government Spending Multipliers}

The vector of endogenous variables reads as follows:

$$
Y_{i, t}=\left[G_{i, t}, G D P_{i, t}, T_{i, t}, S R_{t},(r-g)_{i, t}, F_{t}\right]^{\prime}
$$

where $S R_{t}$, and $F_{t}$ are vectors common to all countries, but that may have a different impact in each country.

Variables $G_{i, t}, G D P_{i, t}$ and $T_{i, t}$ are the three variables traditionally used in the fiscal-VAR literature and represent real government purchases (the sum of government gross fixed capital formation and government consumption), real gross domestic product and real net taxes (the sum of government receipts of direct and indirect taxes minus transfers to businesses and individuals), respectively.

Common variable $S R_{t}$ is the European Central Bank's shadow monetary policy rate developed by $\mathrm{Wu}$ and Xia (2017), which allows us to control for the overall (conventional and unconventional) monetary policy stance in the eurozone. ${ }^{7}$

The addition of $(r-g)_{i, t}$ among the endogenous variables allows us to take the dynamic

\footnotetext{
${ }^{4}$ Due to data availability constraints, we estimate homogeneous slopes of foreign exogenous variables, $z_{t-1}$.

${ }^{5}$ With the data at our disposal, a larger number of lags would prevent the computation of well-behaved generalized impulse response functions.

${ }^{6}$ We limit the analysis to one interaction term given that, as argued by Caggiano et al. (2017), pervasive instability of the estimates are found when working with additional interaction terms.

${ }^{7}$ Since this rate is available from 2004Q3 onward, for the very beginning of the sample, we complement it with the Main Refinancing Operations (MRO) rate, given that the two, until 2008, are virtually indistinguishable.
} 
response of the variable into account when shocking government spending, and ultimately influencing the size of the fiscal multiplier. While we produce the baseline results with an $r-g$ computed as the difference between the ten-year government bond yield and nominal GDP growth relative to the quarter of the previous year, we also conduct robustness checks by replacing the ten-year yield with the average cost of financing the debt (Section 4$){ }^{8}$

Lastly, $F_{t}$ is a $1 \times 5$ vector of common factors extracted from a large number of macroeconomic times series via principal components. Extracting information from a large set of macroeconomic variables mitigates the limited information problem because the principal components proxy the unobserved factors affecting most macroeconomic variables (see Forni et al., 2009 and Fragetta and Gasteiger, 2014 for further details). ${ }^{9}$

Among the exogenous variables, we add the $f_{(t \mid t-1: t-4)}$ series. This represents the forecast of time- $t$ government spending over the past 12 months (four quarters), published by the Economist Intelligence Unit. The addition of this variable represents a way to purge our structural government spending shocks from the change in government spending already anticipated by economic agents in the past year, mitigating the problem known in the literature as fiscal foresight. ${ }^{10}$ Although this device does not control for anticipated movements in government spending beyond the one-year horizon, it alleviates the issue of anticipation insofar as a considerable share of variation of government spending is attributable to expectations formed over the past year. ${ }^{11}$ We add as exogenous variables also a set of U.S. variables, $z_{t-1}$, including the U.S. output gap, U.S. inflation and the U.S. shadow monetary policy rate developed by $\mathrm{Wu}$ and Xia (2016), to account for international factors which may influence our variables of interest.

Our dataset comprises quarterly data and covers the period from 2002Q1 to 2019Q4. ${ }^{12}$ We consider ten of the eleven countries that first joined the EA: Austria, Belgium, Finland,

\footnotetext{
${ }^{8}$ Note that although there is correlation between $G D P$ and $(r-g)$ via $g$ (ranging between -0.51 and -0.85 , depending on the country), collinearity is not an issue because while $G D P_{i, t}$ represents cyclical deviations of real output from trend in a given quarter, $g$ is nominal GDP growth relative to the quarter of the previous year.

${ }^{9}$ Similar to Bernanke et al. (2005), we implement a two-step estimation procedure. As a first step, we extract five common factors, as established by the Bai and $\mathrm{Ng}$ (2007) $I C_{p 2}$ information criterion. The second step is adding the five factors to our vector of endogenous variables.

${ }^{10}$ Fiscal foresight is the phenomenon by which private agents, mainly due to legislative and implementation lags, can anticipate future movements in government spending. Failing to account for them in the identification of what are meant to be unanticipated government spending shocks may give rise to endogeneity and bias the results (see, e.g., Forni and Gambetti, 2010 and Leeper et al., 2013 among others for further details).

${ }^{11}$ For instance, using an estimated DSGE model of the U.S., Schmitt-Grohé and Uribe (2012) attribute 37 percent of the variation of government spending to unexpected shocks, 35 percent to shocks anticipated over the past year, 23 percent to shocks anticipated two years before, and 5 percent to non-fiscal shocks.

${ }^{12}$ The beginning of our sample is dictated by the availability of the Economist Intelligence Unit forecasts of government spending.
} 
France, Germany, Ireland, Italy, Netherlands, Portugal and Spain. In line with Auerbach and Gorodnichenko (2013), we exclude Luxembourg being a small economy, which exhibits large and volatile changes in government spending series. For details on the construction of the dataset, see Appendix A.

To simplify the procedure related to the computation of government spending multipliers, we divide government spending, GDP and net taxes by the real potential GDP of the corresponding country. This way there is no need to take the logarithm of the variables and perform ex-post conversions of the estimated elasticities to euro equivalents, avoiding potential biases. In fact, ex-post conversion requires the use of constant sample averages of the ratios of fiscal variables to GDP, which may instead vary over time, potentially biasing the size of the multipliers. This problem is even more acute in nonlinear models, such as that adopted in this paper (for more details on this issue see, e.g., Gordon and Krenn, 2010 and Ramey and Zubairy, 2018, among others). We compute real potential GDP using the filter recently proposed by Hamilton (2018), but also check whether results are robust to the use of the traditional HP filter (Section 4).

We estimate the model presented in equation (1) using a Bayesian strategy for inference and compute cumulated multipliers as the ratio of discrete approximations of the integral of the median generalized impulse response functions (GIRFs) of real output and government purchases over a given time horizon $h=0,1, \ldots, H:{ }^{13}$

$$
\mathcal{M}_{H}=\frac{\sum_{h=0}^{H} d \operatorname{GDP}(h)}{\sum_{h=0}^{H} d \mathrm{G}(h)} .
$$

For the technical details on inference and identification, see Appendix B.

\section{Results}

This section reports all our baseline results. We start by showing, in Subsection 3.1, impulse responses of important macroeconomic variables to an unexpected shock to government spending, conditional on two regimes: negative and positive $r$ - $g$. Based on these impulse responses, in Subsection 3.2, we compute the associated cumulated government spending multipliers at various time horizons. In Subsection 3.3, we investigate whether the results

\footnotetext{
${ }^{13}$ The government spending shock needed to perturbate the paths of the endogenous variables in the computation of the GIRFs is identified using a Cholesky decomposition (as in Kilian and Vigfusson, 2011 and Caggiano et al., 2017). Following Blanchard and Perotti (2002), we order government spending as the first endogenous variables. The assumption behind this choice is that, due to implementation and legislation lags, government spending does not respond contemporaneously to other endogenous variables within the same quarter.
} 
are driven by the state of the business cycle, the monetary policy stance or the level of public debt.

\subsection{Impulse Responses}

In this subsection we report impulse response functions (IRFs) of government spending, output, net taxes (all in real terms), and of $r-g$ and the shadow monetary policy rate to an unexpected shock to government spending. One of the advantages of the FAIPVAR-X model is that it allows conditioning the IRFs on a specific initial condition. For the purpose of this analysis, the initial condition is represented by $r-g$ in the EA economy being negative or positive.

The left and middle columns of Figure 2 report the IRFs for positive and negative $r-g$ regimes, while the right column reports the difference in the IRFs across the two regimes. A few remarks are in order. First, in both cases a shock to government spending keeps spending itself persistently above baseline and it takes about ten quarters to die out. Second, output and net taxes respond positively to the shock, although the credible set of the responses of net taxes often includes zero. Third, $r-g$ responds positively on impact in both regimes. Afterwards, it increases (albeit not in a statistically significant manner) if the fiscal shock occurs when $r-g>0$, and it falls (to a statistically significant extent) when $r-g<0$. The 90-percent credible set of the difference in the median response of output, net taxes, $r-g$, and the shadow rate, between the negative and positive $r-g$ regimes, excludes zero up to a horizon of 2.5 years or more; it includes zero in the case of government spending, in the first year after the occurrence of the shock.

\subsection{Cumulated Government Spending Multipliers}

Based on these impulse responses, we can compute the cumulated government spending multipliers at several time horizons, as explained in Subsection 2.2. Results are reported in Table 1. Both in the short and the medium term the multiplier is systematically higher if the fiscal shock occurs when $r-g<0$, relative to the case when $r-g>0$. At a one-year horizon, the point estimate is 0.95 in the positive $r-g$ regime and 1.14 in the negative $r-g$ regime. Beyond the one-year horizon, the difference between the two regimes becomes larger with a multiplier of about 0.6 when $r-g>0$ and 1.2 when $r-g<0$.

A fair question is whether the difference between the two sets of multiplier is statistically significant. Bayesian inference does not allow us to construct a test as in the frequentist approach. Therefore, we follow an approach compatible to Bayesian inference. Analogously to Caggiano et al. (2015) and Amendola et al. (2020), we compute empirical distributions of 
Figure 2: Impulse Responses to a Government Spending Shock
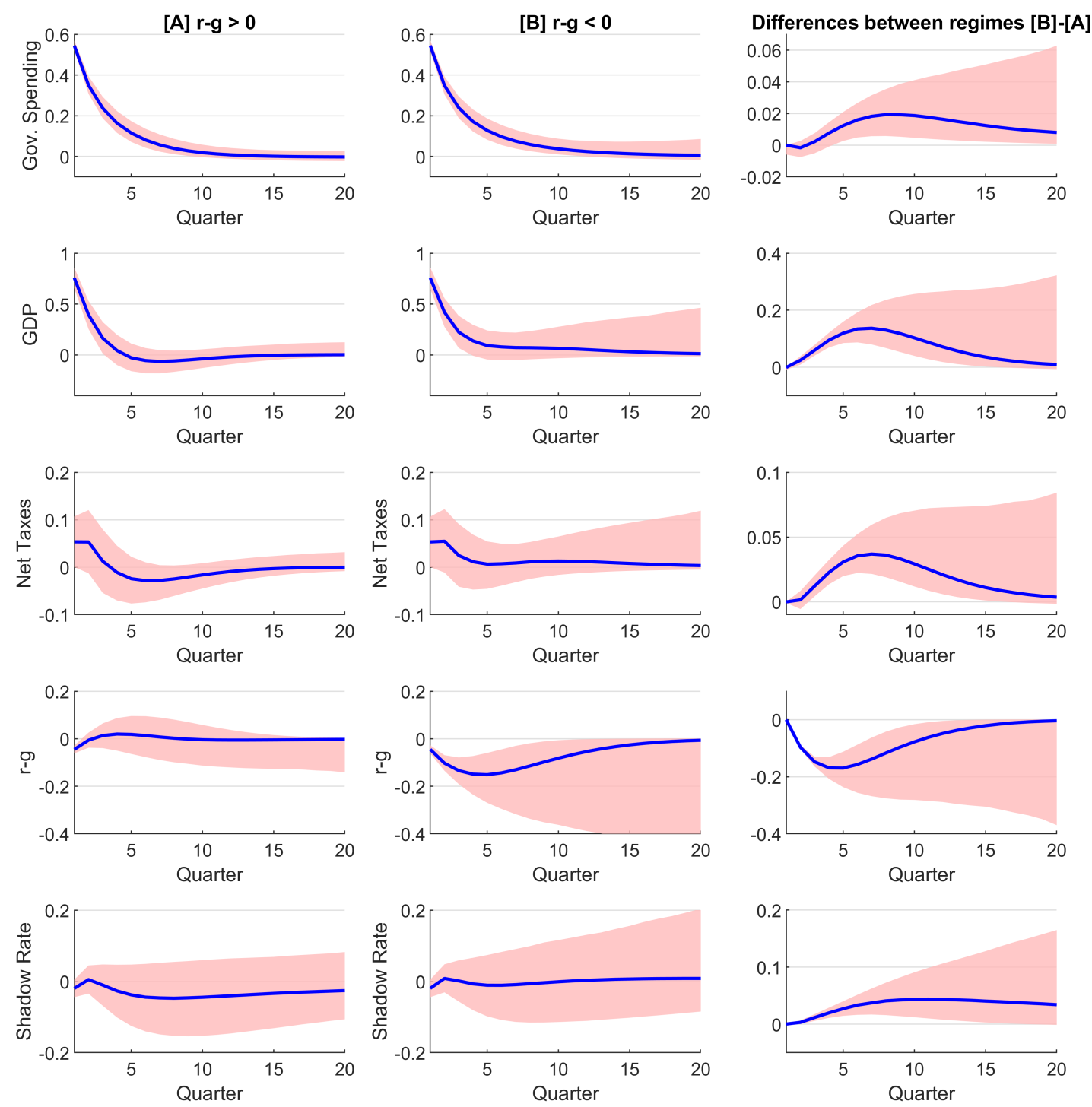

90-percent credible set $\longrightarrow$ Median response

Notes: Impulse responses in percent to a shock of size one standard deviation. Bold lines represent median responses. Shadowed areas represent 90 percent credible sets.

the differences computed as multipliers conditional on the economy being in the negative $r-g$ regime minus multipliers conditional on the economy being in the positive $r-g$ regime, and verify whether a very large part of the distributions include zero or not. In particular, for each of the 10,000 parameter draws from the posterior distribution, we compute the multipliers as in Equation (3), evaluate them for the two regimes, and compute the difference between the 
Table 1: Cumulated Government Spending Multipliers

\begin{tabular}{lccc}
\hline Horizon & $H$ & $r-g>0$ & $r-g<0$ \\
\hline 1 year & 4 & 0.95 & 1.14 \\
2 years & 8 & 0.69 & 1.13 \\
3 years & 12 & 0.61 & 1.18 \\
4 years & 16 & 0.60 & 1.21 \\
5 years & 20 & 0.61 & 1.23 \\
\hline
\end{tabular}

Notes: Multipliers are computed as in Equation (3) for the positive and negative $r-g$ regimes. The table reports median values. $H$ identifies the number of quarters after the shock.

two. Figure 3 plots the distributions of the difference between the two multipliers cumulated at various time horizons together with 90 percent credible sets. It turns out that, at all horizons, at least 90 percent of each distribution is located above zero, indicating that the difference between the two multipliers is positive with very high probability.

With the FAIPVAR-X model, IRFs can also be computed conditional on initial conditions corresponding to specific quarters in the sample. This allows us to compute time series of the cumulated government spending multipliers at various time horizons, over the entire history of the EMU. Figure 4 reports these time series for the whole estimation sample and five times horizons. In line with the average results for the two regimes, these charts highlight an inverse correlation between $r-g$ and the size of the government spending multiplier (the correlation coefficient is 0.92 , on average, across the horizons of cumulated multipliers).

Taken together, these results suggest that in the EA (i) the difference between the size of the government spending multiplier in the negative and positive $r-g$ regimes is different from zero with high probability and economically important; (ii) this difference increases at time horizons beyond the first year; (iii) in the medium-term (5 years), while the multiplier in the positive $r-g$ regime is about 0.6, in the negative $r-g$ regime it is about 1.2. More generally, the multiplier is inversely correlated with $r-g$.

These findings are compatible with theories of forward-looking private agents who expect governments to run larger primary budget balances in the future, if $r-g$ is high at the time of a government spending expansion. Anticipating a fiscal tightening (e.g. higher taxes) agents will save a larger fraction of the increase in income generated by the increase in government expenditures, leading to a smaller fiscal multiplier. 
Figure 3: Distributions of Differences in Cumulated Government Spending Multipliers between Negative and Positive $r-g$ regimes
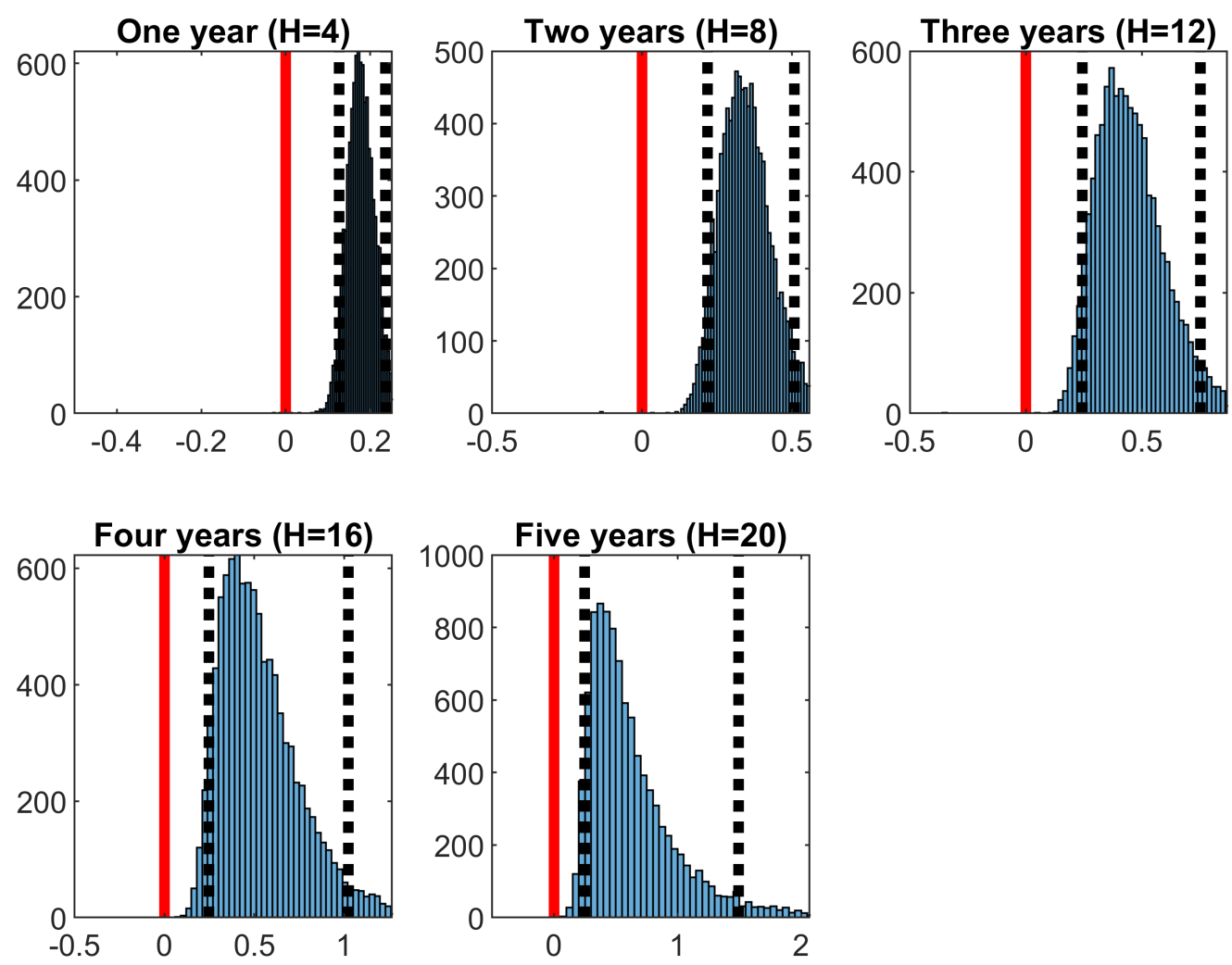

Notes: Empirical distributions of the differences are computed as multipliers conditional on the economy being in the negative $r-g$ regime minus multipliers conditional on the economy being in the positive $r-g$ regime. Multipliers are computed as in Equation (3) for each of the 10,000 parameter draws from the posterior distribution. Vertical dotted lines represent the 5th and the 95th percentiles of the distribution of differences. $H$ identifies the number of quarters after the shock.

\subsection{Impact of the State of the Business Cycle, the Monetary Pol- icy Stance, and the Level of Public Debt}

Given that the literature points at several other determinants of the size of the fiscal multipliers, in this subsection we verify whether the results exaggerate the role of $r-g$, due to the impact of other channels related to $r-g$. We focus on three issues that dominate the literature on state-dependent fiscal multipliers.

1. State of the business cycle. There is a strand of the literature investigating whether government spending multipliers are dependent on the business cycle in advanced 
Figure 4: Historical Evolution of Cumulated Government Spending Multipliers

(a) One year $(H=4)$

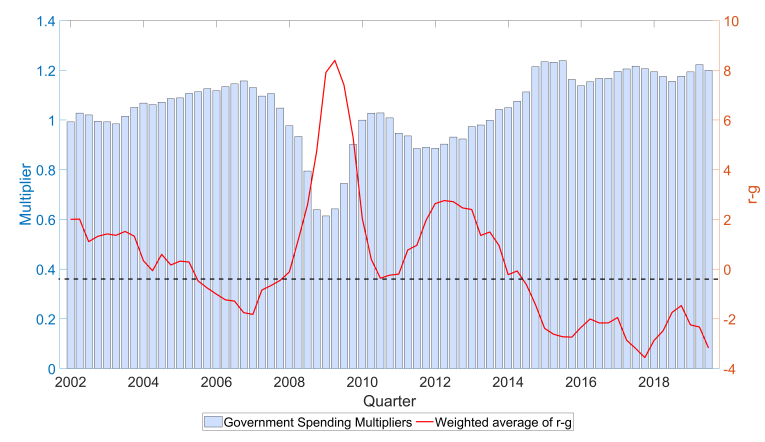

(c) Three years $(H=12)$

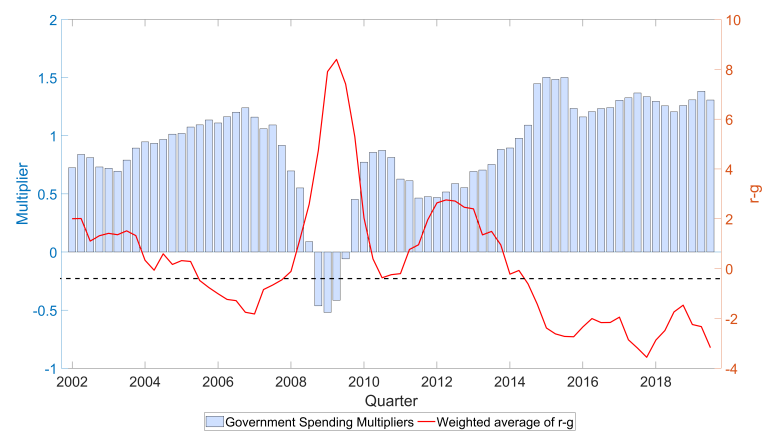

(b) Two years $(H=8)$

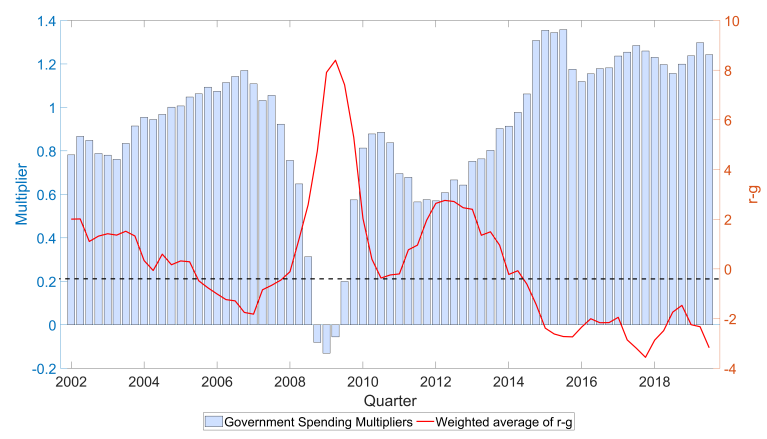

(d) Four years $(H=16)$

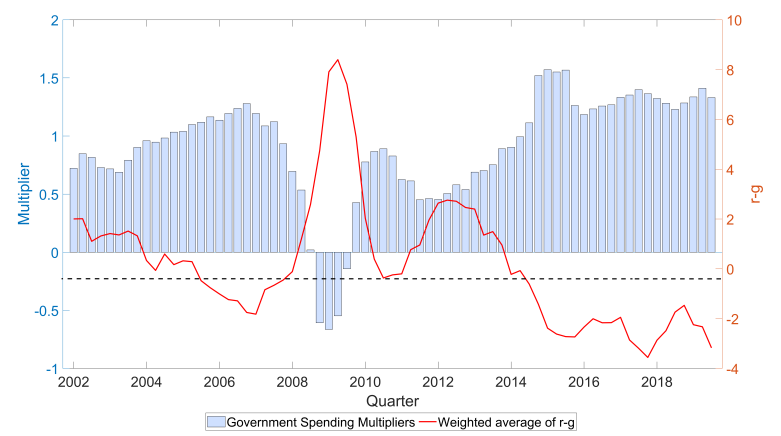

(e) Five years $(H=20)$

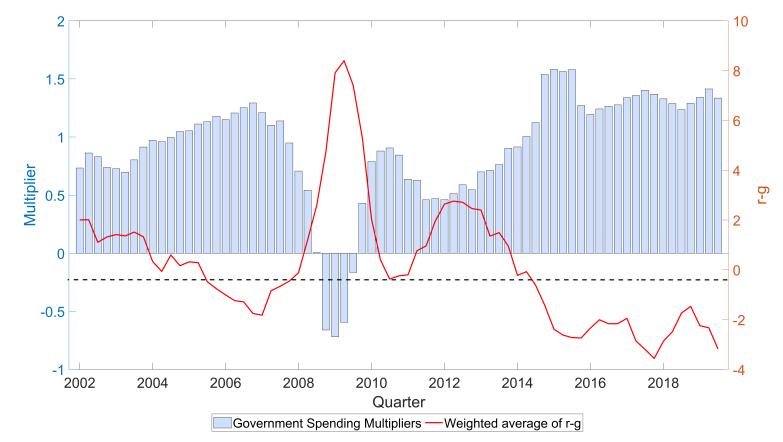

Notes: Multipliers are computed as in Equation (3) conditional on the economy being in a given quarter at the time of the government spending shock. $H$ identifies the number of quarters after the shock.

economies, and in particular whether they are higher in recessions relative to expansions (see Auerbach and Gorodnichenko, 2012, 2013; Batini et al., 2012; Caggiano et al., 2015; Ramey and Zubairy, 2018, among others). Given that $r-g$ is inversely related to the business cycle via the impact of GDP growth (with correlation coefficients ranging between -0.51 and -0.85 , depending on the country), it seems natural to check whether our empirical results are driven by the state of the business cycle through its effect on $r-g$. 
2. Monetary policy stance. Since the Great Recession, with many advanced economies hitting the zero lower bound (ZLB) of the monetary policy rate, several studies have investigated the role of the monetary policy stance on the size of the fiscal multiplier. Both single-country analyses (see, e.g., Crafts and Mills, 2013; Miyamoto et al., 2018; Ramey and Zubairy, 2018; Di Serio et al., 2020, among others), and panel investigations (see, e.g., Almunia et al., 2010, Bonam et al., 2020, Klein and Winkler, 2018, among others) find higher multipliers at the ZLB. In the context of the EA, Amendola et al. (2020) find similar results and establish an inverse association between the shadow monetary policy rate - capturing the overall (conventional and unconventional) monetary policy stance - and the government spending multiplier. Since $r-g$ is affected by monetary policy through its effects on yields, it is appropriate to verify whether the results are dominated by this channel.

3. Level of public debt. The level of public debt is also one of the channels the literature consider important for the size of the fiscal multiplier, with high levels of debt generally associated with smaller multipliers (Kirchner et al., 2010; Nickel and Tudyka, 2014; Fotiou, 2020 and Fotiou et al., 2020, among others). Higher indebtedness generally requires higher yields for government debt issuance, which may lead to a positive correlation between the government debt ratio and $r-g$. On average, in EA data this relationship seems weak (Figure 1, Panel a) with small or even negative correlation coefficients at the country level. However, we still see merit in checking whether the public debt level may be behind the relationship between the multiplier and $r-g$.

From an empirical viewpoint, we use the strategy that Caggiano et al. (2017) employ in the context of uncertainty shocks, and Amendola et al. (2020) use for fiscal multipliers. In practice, in the interaction term that enters equation (1), we substitute $r-g$ with an indicator of each of three abovementioned channels, one at a time: (i) to proxy the stance of the business cycle, we use the output gap measure already present among the endogenous variables of the model; ${ }^{14}$ (ii) to capture the monetary policy stance, we use the shadow monetary policy rate, which is also an endogenous variable; while (iii) public indebtedness is proxied by the ratio of public debt to GDP, which we add also to the vector of endogenous variables (while excluding it from the set of data used to extract the common factors). We estimate the new three models over the same sample as for the baseline analysis, and compute GIRFs and associated fiscal multipliers conditional on positive and negative $r-g$ regimes, using exactly the same quarters that define these regimes in the rest of the paper. If the main driver of our

\footnotetext{
${ }^{14}$ Note that, as explained in Subsection 2.2, in our specification we divide real GDP by the real potential GDP of the corresponding country. Therefore, endogenous variable $G D P_{i, t}$ represents a measure of the output gap.
} 
Table 2: Cumulated Government Spending Multipliers: Alternative Variables in the Interaction Term

\begin{tabular}{|c|c|c|c|c|c|}
\hline \multicolumn{6}{|c|}{ State of the business cycle } \\
\hline \multirow{2}{*}{ Horizon } & \multirow{2}{*}{$H$} & \multirow{2}{*}[\mathrm{A}]{$r-g>0$} & \multirow{2}{*}[\mathrm{B}]{$r-g<0$} & \multicolumn{2}{|c|}{ Distrib. of diff. [B]-[A] } \\
\hline & & & & 5th pctl & 95th pctl \\
\hline 1 year & 4 & 0.25 & 0.43 & -0.20 & 0.47 \\
\hline 2 years & 8 & 0.25 & 0.42 & -0.28 & 0.61 \\
\hline 3 years & 12 & 0.34 & 0.50 & -0.71 & 0.69 \\
\hline 4 years & 16 & 0.40 & 0.56 & -1.40 & 1.06 \\
\hline 5 years & 20 & 0.45 & 0.60 & -1.97 & 1.86 \\
\hline \multicolumn{6}{|c|}{ Monetary policy stance } \\
\hline \multirow{2}{*}{ Horizon } & \multirow{2}{*}{$H$} & \multirow{2}{*}[\mathrm{A}]{$r-g>0$} & \multirow{2}{*}[\mathrm{B}]{$r-g<0$} & \multicolumn{2}{|c|}{ Distrib. of diff. [B]-[A] } \\
\hline & & & & 5th pctl & 95th pctl \\
\hline 1 year & 4 & 1.54 & 1.84 & -0.10 & 0.71 \\
\hline 2 years & 8 & 1.69 & 2.09 & -0.16 & 0.99 \\
\hline 3 years & 12 & 1.86 & 2.31 & -0.21 & 1.20 \\
\hline 4 years & 16 & 1.98 & 2.48 & -0.32 & 1.47 \\
\hline 5 years & 20 & 2.06 & 2.59 & -0.45 & 1.86 \\
\hline \multicolumn{6}{|c|}{ Level of public debt } \\
\hline \multirow{2}{*}{ Horizon } & \multirow{2}{*}{$H$} & \multirow{2}{*}[\mathrm{A}]{$r-g>0$} & \multirow{2}{*}[\mathrm{B}]{$r-g<0$} & \multicolumn{2}{|c|}{ Distrib. of diff. [B]-[A] } \\
\hline & & & & 5th pctl & 95th pctl \\
\hline 1 year & 4 & 1.95 & 1.90 & -0.14 & 0 \\
\hline 2 years & 8 & 1.39 & 1.33 & -0.33 & 0.06 \\
\hline 3 years & 12 & 1.17 & 1.14 & -0.55 & 0.17 \\
\hline 4 years & 16 & 1.23 & 1.23 & -0.69 & 0.31 \\
\hline 5 years & 20 & 1.43 & 1.47 & -0.67 & 0.53 \\
\hline
\end{tabular}

Notes: Multipliers are computed as in Equation (3) for the positive and negative $r-g$ regimes. Multipliers in columns $[\mathrm{A}]$ and $[\mathrm{B}]$ are median values. Differences between multipliers are computed as multipliers conditional on $r-g<0$ minus multipliers conditional on $r-g>0$. Distributions are obtained by computing these differences for each of the 10,000 parameter draws from the posterior distribution. $H$ identifies the number of quarters after the shock.

baseline results were not $r-g$, but rather one of the other three alternative channels, then the multipliers obtained by interacting the alternative macroeconomic indicators should lead to the same conclusions as those obtained by interacting $r-g$. In other words, the difference between the size of the government spending multiplier in the negative and positive $r-g$ regimes should be different from zero with high probability.

As reported in Table 2, it turns out that the multipliers obtained with the alternative three models are rather different from those obtained with the baseline model and, more importantly, the 90-percent credible sets of the difference between the multipliers in the two regimes systematically include zero. In addition, the credible sets widen at longer horizons. 
These results provide evidence that the alternative sets of multipliers are not observationally equivalent to those computed by using $r-g$ in the interaction term of the empirical model. The interest-growth differential has an autonomous role in affecting the size of the EA government spending multiplier.

It is noteworthy to stress that the regimes employed to conduct what is essentially a placebo test, are still $r-g$ regimes and are not dictated by the state of the business cycle, the monetary policy stance or the level of public debt. Therefore, our results should not be interpreted as a contradiction, but rather as a complement to the literature linking the magnitude of fiscal multipliers to other important channels.

\section{Robustness Checks}

In this section we present the results of a number of robustness checks addressing issues commonly discussed in the literature, which may be applicable also to the analysis presented in this paper.

1. Public debt in the specification. In Section 3.3 we report results obtained by including the public-debt-to-GDP ratio among the endogenous variables and replacing $r-g$ with the debt ratio in the interaction term. The rationale for that experiment was to check whether the debt ratio, rather than $r-g$, was the driver of the results. Here, we check whether results are robust to the inclusion of the public debt ratio among the endogenous variables, while keeping $r-g$ in the interaction term (and excluding public debt from the set of data used to extract the common factors). This alternative estimation is motivated by some contributions in the literature that argue in favor of the inclusion of the level of public indebtedness in the specification (e.g. Favero and Giavazzi, 2007).

2. Alternative measure of potential GDP. To facilitate the computation of the multipliers, we divide all government spending, GDP and net taxes by the real potential GDP of the corresponding country. This avoids potential biases that could arise from using constant sample averages of the ratios of fiscal variables to GDP in the ex-post conversion of the estimated elasticities to euro equivalents (see, e.g., Gordon and Krenn, 2010; and Ramey and Zubairy, 2018). In our baseline estimates, we compute real potential GDP using the filter recently proposed by Hamilton (2018). Hodrick (2020) shows that, while Hamilton's filter performs better at identifying the cyclical components in time series environments where the first-differenced series is stationary, the standard HP filter (Hodrick and Prescott, 1997) performs better when the time series

CInternational Monetary Fund. Not for Redistribution 
is generated from a model with unobserved components. Given that the nature of the series under scrutiny may not be easy to ascertain, we check whether results are robust to the use of a standard HP filter.

3. Alternative measure of $r$. Throughout the paper we proxy $r-g$ as the difference between the ten-year government bond yield minus nominal GDP growth computed relative to the quarter of the previous year. Given that several contributions in the literature (e.g. Mauro and Zhou, 2020) use the average cost of financing the public debt in the computation of $r-g$, it seems appropriate to check whether results are robust to this alternative measure. The average cost of financing the public debt is calculated as the ratio between net interest payments and the public debt stock outstanding in the previous quarter. ${ }^{15}$

4. Alternative critical threshold for $r-g$ regimes. Given the intuitive implications of a positive versus negative $r-g$ for public debt dynamics in macroeconomic theory, we use zero as the threshold to distinguish between the two $r-g$ regimes. However, it is worth checking whether the results are robust to adopting an alternative critical threshold, which we set equal to the median value of $r-g$ in the sample, -0.11 . Choosing the mean of 0.19 leads to very similar results.

5. Private investment or consumption in the specification. Our estimation strategy entails parsimony in the number of endogenous variables included in the specification, given the large number of parameters to be estimated. We take agents' information set into account by including factors extracted from a large dataset of macro-financial time series. Given the importance of private demand in the transmission of fiscal shocks, we deem appropriate to include private investment and consumption, one at a time, explicitly in the vector of endogenous variables (after removing them from the computation of factors). This exercise serves two purposes: checking the robustness of the results and shedding light on the transmission channel.

6. Pre-crisis versus post-crisis. The use of the FAIPVAR-X model allows computing multipliers for subsamples of quarters. Given that the estimation period contains the GFC and the Great Recession, it seems appropriate to check whether the results hold for the pre- and post-crisis samples separately. The pre-crisis sample goes from 2002Q1 to 2008Q2, while the post-crisis sample goes from 2008Q3 to 2019 Q4.

\footnotetext{
${ }^{15}$ Mauro and Zhou (2020) adjust $r$ also for exchange rate depreciation, given that their dataset includes countries that issue debt denominated in foreign currency. This is not an issue in the case of the EA countries in our sample.
} 
Figure 5: Impulse Responses of Private Investment and Consumption to a Government Spending Shock

$[A] \mathrm{r}-\mathrm{g}>0$
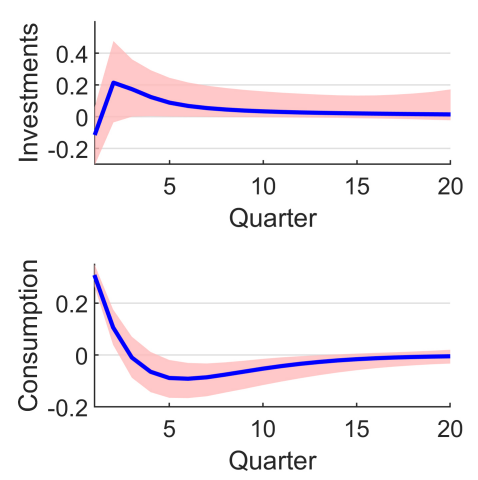

[B] $\mathrm{r}-\mathrm{g}<0$
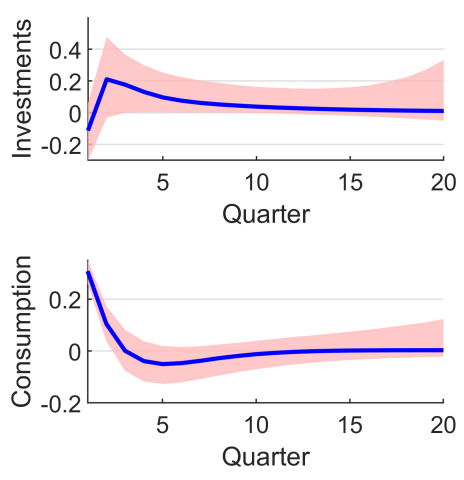

Differences between regimes $[B]-[A]$
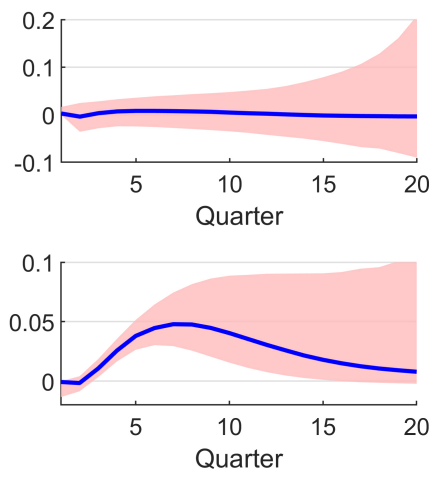

90-percent credible set $\longrightarrow$ Median response

Notes: Impulse responses in percent to a shock of size one standard deviation. Bold lines represent median responses. Shadowed areas represent 90 percent credible sets.

7. High-debt versus low-debt countries. The use of the mean group estimator allows computing multipliers for subsamples of countries. Given that our cross-sectional units contain countries with heterogeneous levels of government debt, it seems natural to verify whether the findings are driven by high-debt countries. Given that there are ten countries in the analysis, we divide the sample in two subsamples with five countries each. The high-debt sample contains the first five countries with the highest average government-debt-to-GDP ratio (Belgium, Ireland, Italy, Portugal and Spain); the lowdebt sample contains the remaining five countries (Austria, Finland, France, Germany and the Netherlands).

As shown in Table 3, subjecting our estimates to these robustness checks changes the median estimates of the multiplier, but does not change the bottom line of the analysis: EA government spending multipliers are systematically larger in the negative $r-g$ regime relative to the positive $r-g$ regime (or in the regime below the median threshold versus the regime above it), with the credible sets of the differences between the two sets of multipliers located largely above zero. In addition, all specifications deliver multipliers with similar magnitudes to the baseline specification.

It is worth noting that explicitly including private investment in the specification delivers slightly higher multipliers in both regimes, while including private consumption delivers virtually the same multipliers as the baseline specification. These exercises are important also for shedding light on the transmission channel. Figure 5 reports the impulse responses of private investment and consumption to a government spending shock in the two regimes. 
Table 3: Robustness Checks on the Cumulated Government Spending Multipliers

\begin{tabular}{|c|c|c|c|}
\hline & & Public debt in the specification & \\
\hline & & & Distrib. of diff. $[\mathrm{B}]-[\mathrm{A}]$ \\
\hline Horizon & $H$ & [A] $r-g>0 \quad[\mathrm{~B}] r-g<0$ & 5th pctl 95th pctl \\
\hline $\begin{array}{l}1 \text { year } \\
2 \text { vears }\end{array}$ & $\begin{array}{l}4 \\
8\end{array}$ & 1.24 & 0.24 \\
\hline $\begin{array}{l}2 \text { years } \\
3 \text { years }\end{array}$ & 12 & 1.08 & 0.75 \\
\hline 4 years & 16 & 1.09 & 0.25 \\
\hline 5 years & 20 & $\begin{array}{ll}1.11 & 1.62 \\
\end{array}$ & 0.25 \\
\hline & & Alternative measure of potential GDF & \\
\hline & & & Distrib. of diff. $[\mathrm{B}]-[\mathrm{A}]$ \\
\hline Horizon & $H$ & [A] $r-g>0$ & 5th petl \\
\hline 1 year & 4 & 0.62 & 0.06 \\
\hline 2 years & 8 & 0.79 & 0.15 \\
\hline $\begin{array}{l}33 \text { years } \\
4 \text { vears }\end{array}$ & 16 & 0.95 & 0.19 \\
\hline $\begin{array}{l}4 \text { years } \\
5 \text { years }\end{array}$ & $\begin{array}{l}10 \\
20\end{array}$ & $\begin{array}{l}1.59 \\
1.77\end{array}$ & 0.18 \\
\hline & & Alternative measure of $r$ & \\
\hline & & & Distrib. of diff. $[\mathrm{B}]-[\mathrm{A}]$ \\
\hline Horizon & $H$ & [A] $r-g>0$ & 5th petl \\
\hline 1 year & 4 & 0.97 & 0.11 \\
\hline 2 years & & 0.83 & 0.21 \\
\hline 3 years & 12 & 0.84 & 0.73 \\
\hline 4 years & & 0.88 & 0.95 \\
\hline 5 years & 20 & 0.91 & 0.20 \\
\hline & & Alternative critical threshold for $r-g$ reg & \\
\hline & & & Distrib. of diff. \\
\hline Horizon & $H$ & [A] $r-g>-0.11$ & 5th petl \\
\hline 1 year & 4 & 0.95 & 0.15 \\
\hline 2 years & 8 & 0.70 & 0.30 \\
\hline 3 years & 12 & 0.63 & 0.34 \\
\hline 4 years & 160 & 1.24 & 0.33 \\
\hline & 20 & $\begin{array}{cc}0.64 & 1.25 \\
\text { Private investment in the specificatiol }\end{array}$ & 0.32 \\
\hline & & 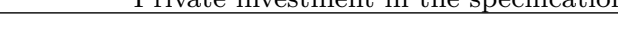 & Distrib. of diff. $|\mathrm{B}-| \mathrm{A}$ \\
\hline Horizon & $H$ & [A] $r-g>0$ & 5th pctl \\
\hline 1 year & 4 & 1.26 & 0.14 \\
\hline 2 years & 8 & 1.05 & 0.27 \\
\hline 3 years & 12 & 0.98 & 0.30 \\
\hline 4 years & 16 & 0.95 & 0.29 \\
\hline 5 years & 20 & $0.95 \quad 1.71$ & 0.28 \\
\hline & & Private consumption in the specificatic & \\
\hline & & {$[A] \quad r \quad a>0$} & Distrib. of diff. $[\mathrm{B}]-[\mathrm{A}]$ \\
\hline Horizon & $H$ & A $] r-g>0$ & 5 th petl \\
\hline $\begin{array}{l}1 \\
2 \\
\text { year } \\
\text { years }\end{array}$ & $\begin{array}{l}4 \\
8\end{array}$ & 0.96 & 0.14 \\
\hline 3 years & 12 & 0.51 & 0.31 \\
\hline 4 years & 16 & 0.50 & 1.53 \\
\hline 5 years & 20 & 1.22 & 0.37 \\
\hline & & Pre-crisis subsample & \\
\hline & & & Distrib. of diff. $[\mathrm{B}]-[\mathrm{A}]$ \\
\hline Horizon & $H$ & [B] $r-g<0$ & 5th pctl \\
\hline 1 year & 4 & $\begin{array}{l}1.04 \\
09\end{array}$ & 0.05 \\
\hline $\begin{array}{l}3 \text { years } \\
\text { years }\end{array}$ & 12 & 0.89 & $\begin{array}{l}0.10 \\
0.12\end{array}$ \\
\hline $\begin{array}{l}3 \text { years } \\
4 \text { years }\end{array}$ & 16 & 0.87 & 0.51 \\
\hline 5 years & 20 & 0.89 & 0.70 \\
\hline & & Post-crisis subsample & \\
\hline & & & Distrib. of diff. $[\mathrm{B}]-[\mathrm{A}]$ \\
\hline Horizon & $H$ & [B] $r-g<0$ & 5th pctl \\
\hline 1 year & 4 & 0.88 & 0.21 \\
\hline 2 years & 8 & 0.54 & 0.42 \\
\hline $\begin{array}{l}3 \text { years } \\
4 \text { years }\end{array}$ & 12 & 0.42 & 0.47 \\
\hline 4 years & & 0.40 & 0.47 \\
\hline 5 years & 20 & 0.41 & 0.45 \\
\hline & & High-debt subsample & \\
\hline & & & Distrib. of diff. $[\mathrm{B}]-[\mathrm{A}]$ \\
\hline Horizon & $H$ & [B] $r-g<0$ & 5th pctl \\
\hline year & 4 & 0.86 & 0.20 \\
\hline 2 years & 8 & 0.50 & 0.40 \\
\hline $\begin{array}{l}3 \text { years } \\
4 \text { years }\end{array}$ & 16 & $\begin{array}{l}0.37 \\
0.34\end{array}$ & 0.45 \\
\hline 5 years & 20 & $\begin{array}{l}0.34 \\
0.35\end{array}$ & 0.44 \\
\hline & & Low-debt subsample & \\
\hline & & & Distrib. of diff. $[\mathrm{B}]-[\mathrm{A}]$ \\
\hline Horizon & $H$ & [B] $r-g<0$ & 5th pctl \\
\hline 1 year & 4 & 1.13 & 0.11 \\
\hline 2 years & 8 & 0.79 & 0.22 \\
\hline 3 years & 12 & 0.74 & 0.25 \\
\hline 4 years & 16 & 1.20 & 1.06 \\
\hline 5 years & 20 & 1.21 & 0.24 \\
\hline
\end{tabular}


It turns out that while the credible set of the difference between the responses of private investment across the two regimes include zero, the credible set of the difference between the responses of private consumption in the negative and positive $r-g$ regimes excludes zero in several quarters. This finding hints that the different response of private agents' consumption, rather than that of private investment, is behind the different multipliers across the two regimes.

Regarding the subsample analysis, it should be mentioned that the difference between multipliers in the negative and positive $r-g$ regimes is larger in the post-crisis than in the pre-crisis subsample; and again larger in the high-debt than in the low-debt subsample. In addition, while low-debt and high-debt countries have very similar multipliers in the negative $r-g$ regime, low-debt countries exhibit higher multipliers than high-debt countries in the positive $r-g$ regime. This finding hints that a high level of debt may aggravate the impact of a positive $r-g$ on the size of the multipliers via expectations of future fiscal retrenchments. ${ }^{16}$

In sum, across all estimation variants (including the baseline reported in Subsection 3.2), median estimates of the multipliers vary conditional on the specification, but the difference between the multiplier in the negative and positive $r-g$ regimes is economically important and different from zero with high probability. Considering full-sample estimates, over the medium run (5 years), median cumulated multipliers range between 0.51 and 1.26 in the positive $r-g$ regime, and between 1.22 and 1.77 in the negative $r-g$ regime.

\section{Conclusions}

Academic studies and policy analyses contributed to a lively debate on potential fiscal stimuli that dates back to well before the COVID-19 pandemic. The arguments in favor of more ambitious stimuli often gravitated around the negative $r-g$ recorded in many countries, while opposing views were rooted in the historically high public debt levels.

The pandemic made fiscal expansions a necessity, as governments had to tackle not only the health emergency per se, but also the economic fallout triggered by lockdowns and other mitigation measures. Despite unprecedented government interventions, there is a risk that COVID-19 may leave deep economic scars. Therefore, policymakers around the globe committed to accelerate the recovery with programs that will ultimately increase government expenditures and may bring debt to even higher levels. Whether government

\footnotetext{
${ }^{16}$ This mechanism is in line with the findings of Huidrom et al. (2020), who show that weak fiscal positions can lower fiscal multipliers through a Ricardian channel, which implies that households lower consumption in expectation of fiscal consolidation; and an interest rate channel which implies that investor concerns about sovereign risk raise borrowing costs.
} 
spending programs will be successful depends on the size of fiscal multipliers, not only due to their first-round implications for GDP, but also due to the effect that GDP growth has on debt sustainability through $r-g$.

Exploiting data on ten EA countries, this paper shows that a higher $r-g$ is associated with a lower government spending multiplier and viceversa. This empirical finding is in line with economic theories assuming forward-looking agents who anticipate that the higher $r-g$, the higher the primary budget balance a government needs to run to stabilize its debt. We find the difference between the size of the multiplier in the negative and positive $r-g$ regimes to be systematically different from zero with high probability, and to increase at time horizons beyond the first year. Median cumulated multipliers range between 0.51 and 1.26 in the positive $r-g$ regime, and between 1.22 and 1.77 when $r-g$ is negative, depending on the specification.

These calculations are based on the estimates of a factor-augmented interacted panel vector-autoregressive model. The econometric approach deals with several technical problems highlighted in the empirical macroeconomic literature, including the issues of fiscal foresight and limited information. Placebo-like tests confirm that the findings are not driven by the state of the business cycle, the monetary policy stance, or the level of government debt, and they survive a number of other robustness checks.

The results carry important policy implications especially in the context of the usage of the EU Recovery Fund, which will lead to ambitious government spending programs in member countries. With GDP growth expected to resume, insofar as interest rates remain low, the resulting $r-g$ should be conducive of relatively high government spending multipliers. However, this scenario may be reversed, and multipliers may become significantly more modest, if adverse shocks keep $r-g$ significantly above zero in large member countries.

\section{References}

Almunia, M., A. Benetrix, B. Eichengreen, K. H. O’Rourke, and G. Rua (2010, April). From Great Depression to Great Credit Crisis: Similarities, Differences and Lessons. Economic Policy 25, 219-265.

Amendola, A., M. Di Serio, M. Fragetta, and G. Melina (2020). The Euro-Area Government Spending Multiplier at the Effective Lower Bound. European Economic Review 127, 103480.

Auerbach, A. J. and Y. Gorodnichenko (2012). Measuring the Output Responses to Fiscal Policy. American Economic Journal: Economic Policy 4(2), 1-27.

Auerbach, A. J. and Y. Gorodnichenko (2013). Fiscal Multipliers in Recession and Expansion. In A. Alesina and F. Giavazzi (Eds.), Fiscal Policy after the Financial Crisis, pp. 63-98. University of Chicago Press. 
Bai, J. and S. Ng (2007). Determining the Number of Primitive Shocks in Factor Models. Journal of Business and Economic Statistics 25(1), 52-60.

Barrett, P. (2018). Interest-Growth Differentials and Debt Limits in Advanced Economies. IMF Working Paper 18/82.

Batini, N., G. Callegari, and G. Melina (2012). Successful Austerity in the United States, Europe and Japan. IMF Working Paper 190.

Bernanke, B. S., J. Boivin, and P. S. Eliasz (2005). Measuring the Effects of Monetary Policy: a Factoraugmented Vector Autoregressive (FAVAR) approach. The Quarterly Journal of Economics 120, 387-422.

Blanchard, O. (2019, April). Public Debt and Low Interest Rates. American Economic Review 109(4), 1197-1229.

Blanchard, O. J. and R. Perotti (2002). An Empirical Characterization of the Dynamic Effects of Changes in Government Spending and Taxes on Output. Quarterly Journal of Economics 117(4), 1329-1368.

Bonam, D., J. De Haan, and B. Soederhuizen (2020). The Effects of Fiscal Policy at the Effective Lower Bound. Macroeconomic Dynamics, 1-37.

Caggiano, G., E. Castelnuovo, V. Colombo, and G. Nodari (2015). Estimating Fiscal Multipliers: News From A Non-linear World. Economic Journal 125(584), 746-776.

Caggiano, G., E. Castelnuovo, and G. Pellegrino (2017). Estimating the Real Effects of Uncertainty Shocks at the Zero Lower Bound. European Economic Review 100, 257-272.

Canova, F. and M. Ciccarelli (2013). Panel Vector Autoregressive Models: A Survey. In VAR Models in Macroeconomics-New Developments and Applications: Essays in Honor of Christopher A. Sims, pp. 205-246. Emerald Group Publishing Limited.

Cogley, T. and T. J. Sargent (2005). Drift and Volatilities: Monetary Policies and Outcomes in the Post WWII U.S. Review of Economic Dynamics 8, 262-302.

Crafts, N. and T. C. Mills (2013, December). Rearmament to the Rescue? New Estimates of the Impact of "Keynesian" Policies in 1930s' Britain. The Journal of Economic History $73(4), 1077-1104$.

Del Negro, M. and F. Schorfheide (2011). Bayesian Macroeconometrics. In J. Geweke, G. Koop, and H. V. Dijk (Eds.), The Oxford Handbook of Bayesian Econometrics. Oxford University Press.

Di Serio, M., M. Fragetta, and E. Gasteiger (2020, December). The Government Spending Multiplier at the Zero Lower Bound: Evidence from the United States. Oxford Bulletin of Economics and Statistics 82(6), 1262-1294.

Dickey, D. A. and W. A. Fuller (1979). Distribution of the Estimators for Autoregressive Time Series With a Unit Root. Journal of the American Statistical Association 74(366), 427-431.

Favero, C. and F. Giavazzi (2007, January). Debt and the Effects of Fiscal Policy. Working Paper 12822, National Bureau of Economic Research.

Forni, M. and L. Gambetti (2010, May). Fiscal Foresight and the Effects of Goverment Spending. CEPR Discussion Papers 7840, C.E.P.R. Discussion Papers.

Forni, M., D. Giannone, M. Lippi, and L. Reichlin (2009). Opening the Black Box: Structural Factor Models with Large Cross Sections. Econometric Theory 25, 1319-1347.

Fotiou, A. (2020, November). Non-Linearities in Fiscal Policy:The Role of Debt. IMF Working Papers 2020/246, International Monetary Fund. 
Fotiou, A., W. Shen, and S.-C. S. Yang (2020). The Fiscal State-Dependent Effects of Capital Income Tax Cuts. Journal of Economic Dynamics and Control 117, 103860.

Fragetta, M. and E. Gasteiger (2014). Fiscal Foresight, Limited Information and the Effects of Government Spending Shocks. Oxford Bulletin of Economics and Statistics 76(5), 667692.

Gordon, R. J. and R. Krenn (2010). The End of the Great Depression 1939-41: Policy Contributions and Fiscal Multipliers. NBER Working Paper 16380, National Bureau of Economic Research.

Hamilton, J. D. (2018). Why You Should Never Use the Hodrick-Prescott Filter. Review of Economics and Statistics 100(5), 831-843.

Hodrick, R. J. (2020, February). An Exploration of Trend-Cycle Decomposition Methodologies in Simulated Data. Working Paper 26750, National Bureau of Economic Research.

Hodrick, R. J. and E. C. Prescott (1997). Postwar U.S. Business Cycles: An Empirical Investigation. Journal of Money, Credit and Banking 29(1), 1-16.

Huidrom, R., M. A. Kose, J. J. Lim, and F. L. Ohnsorge (2020). Why Do Fiscal Multipliers Depend on Fiscal Positions? Journal of Monetary Economics 114, 109-125.

Kilian, L. and R. J. Vigfusson (2011). Are the Responses of the US Economy Asymmetric in Energy Price Increases and Decreases? Quantitative Economics 2(3), 419-453.

Kirchner, M., J. Cimadomo, and S. Hauptmeier (2010). Transmission of Government Spending Shocks in the Euro Area: Time Variation and Driving Forces. Working Paper Series 1219, European Central Bank.

Klein, M. and R. Winkler (2018, January). The Government Spending Multiplier at the Zero Lower Bound: International Evidence from Historical Data. Working Papers 2018001, University of Antwerp, Faculty of Business and Economics.

Koop, G., M. H. Pesaran, and S. M. Potter (1996). Impulse Response Analysis in Nonlinear Multivariate Models. Journal of econometrics 74(1), 119-147.

Kwiatkowski, D., P. C. B. Phillips, P. Schmidt, and Y. Shin (1992). Testing the Null Hypothesis of Stationarity Against the Alternative of a Unit Root: How Sure Are We That Economic Time Series Have a Unit Root? Journal of Econometrics 54(1-3), 159178.

Leeper, E. M., T. B. Walker, and S. C. S. Yang (2013). Fiscal Foresight and Information Flows. Econometrica 81(3), 1115-1145.

Lian, W., A. F. Presbitero, and U. Wiriadinata (2020, July). Public Debt and r - g at Risk. IMF Working Papers 2020/137, International Monetary Fund.

Mauro, P. and J. Zhou (2020, March). r minus g negative: Can We Sleep More Soundly? IMF Working Papers 2020/052, International Monetary Fund.

Miyamoto, W., T. L. Nguyen, and D. Sergeyev (2018, July). Government Spending Multipliers under the Zero Lower Bound: Evidence from Japan. American Economic Journal: Macroeconomics 10(3), 247-77.

Nickel, C. and A. Tudyka (2014). Fiscal Stimulus in Times of High Debt: Reconsidering Multipliers and Twin Deficits. Journal of Money, Credit and Banking 46(7), 1313-1344.

Pesaran, M. H. and R. Smith (1995). Estimating Long-Run Relationships From Dynamic Heterogeneous Panels. Journal of econometrics 68(1), 79-113.

Ramey, V. A. and S. Zubairy (2018). Government Spending Multipliers in Good Times and in Bad: Evidence from US Historical Data. Journal of Political Economy 126(2), 850-901. 
Rogoff, K. (2020). Falling Real Interest Rates, Rising Debt: A free lunch? Journal of Policy Modeling 42(4), 778 - 790. SI: Growth and Trade in the United States and Europe.

Sá, F., P. Towbin, and T. Wieladek (2014, apr). Capital Inflows, Financial Structure and Housing Booms. Journal of the European Economic Association 12(2), 522-546.

Schmitt-Grohé, S. and M. Uribe (2012, November). What's News in Business Cycles. Econometrica $80(6)$, 2733-2764.

Stock, J. H. and M. W. Watson (2005). Implications of Dynamic Factor Models for VAR Analysis. NBER Working Papers 11467.

$\mathrm{Wu}$, J. C. and F. D. Xia (2016). Measuring the Macroeconomic Impact of Monetary Policy at the Zero Lower Bound. Journal of Money, Credit and Banking 48(2-3), 253-291.

Wu, J. C. and F. D. Xia (2017). Time-Varying Lower Bound of Interest Rates in Europe. Chicago Booth Research Paper No. 17-06.

\section{Appendix}

\section{A Data}

\section{A.1 Endogenous Variables}

Our variables of interest are gross domestic product, net taxes, government spending, the European Central Bank's shadow rate and the interest-growth differential. As standard in the literature we construct net taxes as the sum of government receipts of direct and indirect taxes minus transfers to businesses and individuals. The government spending series is constructed as the sum of government gross fixed capital formation and government consumption. The interest-growth differential $(r-g)$, which is present also in our interaction term, is constructed as the difference between the 10-year Government Bond Yield and yearon-year GDP growth. In our robustness analysis, we also employ an alternative measure of $r$, computed as the ratio between net interest payments and the public debt stock outstanding in the previous quarter. All the variables are downloaded from the Eurostat database available on the Thomson Reuters Datastream Economics database. Gross domestic product, net taxes and government spending are transformed in real terms using the implicit GDP price deflator. Then they are normalized by diving by real potential GDP. The European Central Bank's shadow rate, is that developed by Wu and Xia (2017).

\section{A.2 Exogenous Variables}

We use as exogenous variables the forecast of the annualized growth rate of total government expenditure over GDP produced by the Economist Intelligence Unit. In particular, we create a series where in each quarter we compute the average forecast for the current year over the 
past 12 months. The other exogenous variables are the U.S. output gap, and the U.S. inflation downloaded from the Federal Reserve Bank of St. Louis database, and the U.S. Shadow Rate developed by Wu and Xia (2016).

\section{A.3 Informational Dataset}

The informational dataset we used to extract common factors is composed by 250 series downloaded from the Eurostat database available on the Thomson Reuters Datastream Economics database. Specifically we downloaded the following variables for each country considered:

- National Account: Domestic Demand; Export of Goods and Services; Imports of Goods and Services; Gross Capital Formation; Final Consumption Expenditure of Households.

- Government Statistics: Government Consolidated Gross Debt: Central Govt.

- Output and income: Industrial Production Index (Mining and Quarrying; Manufacturing; Electricity, Gas, Steam and Air Conditioning Supply); Nominal Unit Labor Cost based on persons; Production - Total Industry Excl. Construction; Production of Total Construction; Wages and Salaries; Change in Inventories.

- Employment and hours: Early Estimates of Labor Productivity - Total Economy; Employees Domestic Concept; Unemployment: Total.

- Stock prices: S\&P BMI - Price Index.

- Exchange rates: REER: 19 trading partners EA; NEER: 37 Trading Partners.

- Money and credit quantity aggregates: Money Supply: M1 - Contribution to Euro M1; Money Supply: M2 - Contribution to Euro M2; Money Supply: M3 - Contribution to Euro M3; Official Reserve Assets.

- Interest Rate: Harmonized Government 10-Year Bond Yield.

Where appropriate we transform variables to guarantee stationarity tested by the Dickey and Fuller (1979) and Kwiatkowski et al. (1992) tests.

\section{B Inference and Identification}

We estimate the FAIPVAR-X model presented in equation (1), adopting the following three steps. 
1. Estimate the reduced-form model adopting a Bayesian strategy for inference with an uninformative independent Normal-Wishart prior, which in turn uses a Montecarlo simulation to recover the posterior distribution of the parameters. ${ }^{17}$ More precisely, adopt a Direct Monte Carlo Sampling to draw the variance-covariance matrix of the residuals after averaging coefficients across countries, $\Sigma^{(s)}$, from an inverse Wishart distribution $I W(\hat{S}, T \times N-f)$-where $\hat{S}$ is the sum of the squared residuals and $f$ is the number of coefficients in a single equation of the VAR - for drawing $\Phi^{(s)}$ from the conditional multivariate normal distribution $M N\left(\hat{\Phi}, \Sigma^{(s)} \otimes\left(X^{\prime} X\right)^{-1}\right)$, where $\hat{\Phi}$ are the estimated reduced-form parameters and $X$ is the matrix of regressors in the panel VAR. $^{18}$

2. Make a draw of the posterior distribution and derive Generalized Impulse Response Functions (GIRFs) following the methodology of Koop et al. (1996) and Caggiano et al. (2017). This approach allows endogenizing the variables in the interaction term and, consequently, conditioning the response of the other endogenous variables on their evolution. Specifically, GIRFs are derived as the following difference:

$$
G I R F_{i, y}\left(h, \delta, \omega_{i, t-1}\right)=E\left[y_{i, t+h} \mid \delta, \omega_{i, t-1}\right]-E\left[y_{i, t+h} \mid \omega_{i, t-1}\right]
$$

where, for each country $i, E\left[y_{i, t+h} \mid \delta, \omega_{i, t-1}\right]$ represents the expected value of the response of the endogenous variables $y$ to a shock of size $\delta$, at horizon $t+h$, conditional on an initial history $\omega_{t-1}$; and $E\left[y_{t+h} \mid \omega_{i, t-1}\right]$ represents the expected value of the endogenous variable $y$ at horizon $t+h$ conditional on an initial history $\omega_{t-1}$. It is worth emphasizing that the vector of endogenous variables $y$ also includes the variables in the interaction term, and that the choice of the initial condition $\omega_{i, t-1}=\left\{y_{t-1}, \ldots, y_{t-k}\right\}$ allows discerning among different monetary policy regimes. Thus, for each country and each regime:

(a) pick an initial condition $\omega_{t-1, j}$;

(b) simulate the residuals series starting from its empirical distribution $\tilde{u}_{t+h}^{r} \sim d(0, \widehat{\Sigma})$;

(c) for each simulation of residuals $r$, recover the path $E\left[y_{t+h, j} \mid \omega_{t-1, j}\right]^{r}$;

(d) simulate the path $E\left[y_{t+h, j} \mid \delta, \omega_{t-1, j}\right]^{r}$ starting from the residuals obtained in substep (b) perturbated by a government spending shock identified using a Cholesky decomposition (as in Kilian and Vigfusson, 2011 and Caggiano et al., 2017); ${ }^{19}$

\footnotetext{
${ }^{17}$ As in Cogley and Sargent (2005); Sá et al. (2014), we discard any explosive draws from the unrestricted posterior.

${ }^{18}$ For further details see Algorithm 2.1 described in Del Negro and Schorfheide (2011).

${ }^{19}$ Following Blanchard and Perotti (2002), we order government spending as the first endogenous variables.
} 
(e) compute the GIRF as in equation B.1;

(f) compute the average GIRF across $R=500$ simulations in order to obtain consistent estimates; ${ }^{20}$

(g) average across countries once the average GIRF for each initial condition belonging to different regimes has been collected.

3. Repeat step 2 for 10,000 draws from the posterior distribution. Then consider the median IRFs across the 10,000 parameter draws. Parameter uncertainty is accounted for by saving the 5th and 95th percentile of the distribution as error bands.

The assumption behind this choice is that, due to implementation and legislation lags, government spending does not respond contemporaneously to other endogenous variables within the same quarter.

${ }^{20}$ As in Caggiano et al. (2017), if a given initial condition produce an explosive response, we discard it. 